\title{
Duodenogastric reflux and gastric stump carcinoma
}

\author{
Ken Kondo \\ Deptartment of Surgery, Nagoya National Hospital, 1-1 San-nomaru 4-chome, Naka-ku, Nagoya 460-0001, Japan
}

\begin{abstract}
Gastric stump carcinoma after gastric surgery for benign disease is now widely recognized as a distinct clinical entity. The stump carcinoma was often found to be localized to the anastomosis, known to be the site with severe duodenogastric reflux. For this reason, duodenogastric reflux, including the reflux of bile and pancreatic juice, after a Billroth II procedure for benign disease is frequently discussed as an important factor related to the development of stump carcinoma. Many experiments have implicated bile acids, the main component of the duodenal juice, in gastric carcinogenesis. In particular, rat models without the use of the carcinogen, $\mathbf{N}$-methyl-N' nitro-N-nitrosoguanidine (MNNG), showed adenocarcinoma in the remnant stomach that was related to the severity of duodenogastric reflux. However, human data are, inevitably, much less consistent. Whether the incidence of stump carcinoma is higher than that of gastric carcinoma in general is still controversial. Concerning the histogenesis of stump carcinoma after benign disease, a relationship between gastritis cystica polyposa (GCP) and gastric type adenocarcinoma has been suggested. Recently, the population at risk of gastric stump carcinoma for benign disease has been diminishing significantly, and the incidence of gastric stump carcinoma after surgery for malignant disease has been increasing. The influence of duodenogastric reflux in the gastric remnant after malignant disease may differ from its influence in the gastric remnant after benign disease. Further clinical study is needed to elucidate the pathogenetic factors involved in gastric stump carcinoma.
\end{abstract}

Key words Gastric stump carcinoma - Duodenogastric reflux • Billroth II procedure

Offprint requests to: $\mathrm{K}$. Kondo

Received: July 30, 2001 / Accepted: October 16, 2001

\section{Introduction}

In the early 1950s, reports of cases of carcinoma developing in the gastric remnant after gastrojejunostomy (Billroth II; B II) or gastroduodenostomy (Billroth I; B I) began to appear in the literature [1,2]. "Gastric stump carcinoma" is now widely recognized as a carcinoma developing in the gastric remnant after gastrectomy for benign disease. The stump carcinoma was often localized to the anastomosis, known to be the site of severe duodenogastric reflux. For this reason, the argument has been made about the role of duodenogastric reflux as an important causal factor in gastric carcinogenesis for many years. However, the relationship between duodenogastric reflux and gastric cancer has not yet been defined from human data. From the standpoint of surgeons, this matter is also related to the surgical technique to be chosen.

Accordingly, the influence of duodenogastric reflux, including the reflux of bile and pancreatic juice, on the remnant stomach should be studied further from various clinical standpoints and in terms of molecular biology. This review examines the literature, noting substantial evidence for the role of duodenogastric reflux in gastric carcinogenesis in animal experiments and in clinical evidence related to stump carcinoma.

\section{Epidemiological features of stump carcinoma}

Whether the incidence of stump carcinoma is higher than that of gastric carcinoma in general is still controversial [3]. European reports have indicated an increased risk of the development of stump carcinoma with time after surgery for benign disease [4-6]. Several authors [6,7] have found the incidence of stump carcinoma to be unaffected by the operative procedure. But in large cohorts with long follow-up (more than 20 years after operation), it has been revealed that gastric stump 
carcinoma was found preferentially on the gastric mucosa near the gastroenteric stoma created by the B II procedure $[8,9]$.

In Japan, the increased risk of stump carcinoma has not been verified, while many gastrectomies have been done for gastric cancer. Tokudome et al. [10] reported that the ratio of observed to expected deaths from gastric stump carcinoma was less than 1.0, and no difference in mortality was shown according to the operative procedure. Asano et al. [11] reported that, in a followup of 6662 gastrectomized patients, with an average observation period of 13.1 years, the risk of carcinoma mortality was lower than that in the general population. This trend was not affected by either the initial disease or by the operative procedure. In order to study the incidence of stump carcinoma, we surveyed the same cohort as that surveyed by Asano et al. [11]; patients who had survived for more than 20 years after gastrectomy were surveyed. The incidence of carcinoma in male patients who had undergone the B II procedure when they were less than 40 years old was four times higher than that in male patients who had undergone the B I procedure at the same age [12]. Although the difference was not significant, a causal association between the B II procedure with duodenogastric reflux and the development of stump carcinoma may be suspected.

\section{Clinicopathological features of stump carcinoma}

In the examination of re-operated patients, it has been found that most carcinomas occurred after a retrocolic B II procedure without Braun's anastomosis [13,14]. Hammar [15] investigated the localization of stump carcinomas and precancerous changes after B II in 56 patients and after B I in 5 patients. And showed a typical site of carcinoma growth within the B II stoma extending toward the posterior wall near the efferent loop. Japanese reports have shown that patients reconstructed with the B II procedure developed significantly more carcinomas in the stoma than those reconstructed with the B I procedure $[12,16]$. The location of stump carcinomas close to the B II stoma suggests duodenogastric reflux involvement in gastric carcinogenesis.

Several reports have indicated that carcinoma occurred earlier after surgery for gastric ulcer than after surgery for duodenal ulcer $[13,17]$. The mucosa in gastric ulcer patients manifests a high degree of atrophic gastritis, in contrast to that in duodenal ulcer patients, and this might account for the earlier development of carcinoma in the gastric ulcer patients $[13,18]$. In a large cohort, at 20 or more years after surgery, an increased risk of cancer was found in duodenal ulcer patients, as well as in those with gastric ulcer [5,7]. Janunger et al. [19] showed that the differences between the remnant mucosa after duodenal and gastric ulcer surgeries vanished after about 20 years.

Histologically, most advanced carcinomas show the diffuse type of carcinoma, although intestinal metaplasia is rare in the fundic gland area $[15,20]$. On the other hand, the intestinal type of carcinoma is more common in early stump carcinoma that occurs a long time after the primary surgery $[15,21]$.

Stump carcinoma after primary surgery for malignant disease is characterized by a shorter interval after the surgery and by location away from the stoma compared with the features of stump carcinoma after primary surgery for benign disease. The reason for these differences is that patients with gastric carcinoma already have carcinoma-related gastric mucosal changes at the time of the primary surgery. Thus, gastric stump carcinoma after benign disease develops as a new lesion, while that after malignant disease may be a metachronous multiple lesion [22,23].

\section{Animal models of duodenogastric reflux with carcinogen}

Carcinogenesis is believed to begin with a mutation caused by an injury to DNA. This first step is called "initiation." The second step needed for carcinogenesis is "promotion" of the initial cancerous cells [24]. Sugimura and Fujimura [25] first induced stomach carcinomas in rats, using $\mathrm{N}$-methyl-N'-nitro-Nnitrosoguanidine (MNNG) as an initiator. Since then, gastric carcinogenesis has been studied extensively in animals.

To determine the pathogenetic role of duodenogastric reflux, experimental models of the development of gastric stump carcinoma with various operative procedures have also been devised [26,27]. Nishidoi et al. [28] reported that, after the oral administration of MNNG, the incidence of gastric carcinoma in Wistar rats was significantly higher in those animals that had the B II procedure than in those that had the long Rouxen-Y procedure. Even when MNNG was given after the operation, most carcinomas were found in rats operated with the B II procedure [29,30]. The experiments showed that animals receiving MNNG and the B-II procedure had a significantly higher incidence of gastric stump carcinoma than control animals without MNNG and with other operative procedures. These findings demonstrate that, in rats, gastrectomy promotes gastric carcinogenesis by a mechanism that involves continual duodenogastric reflux. 

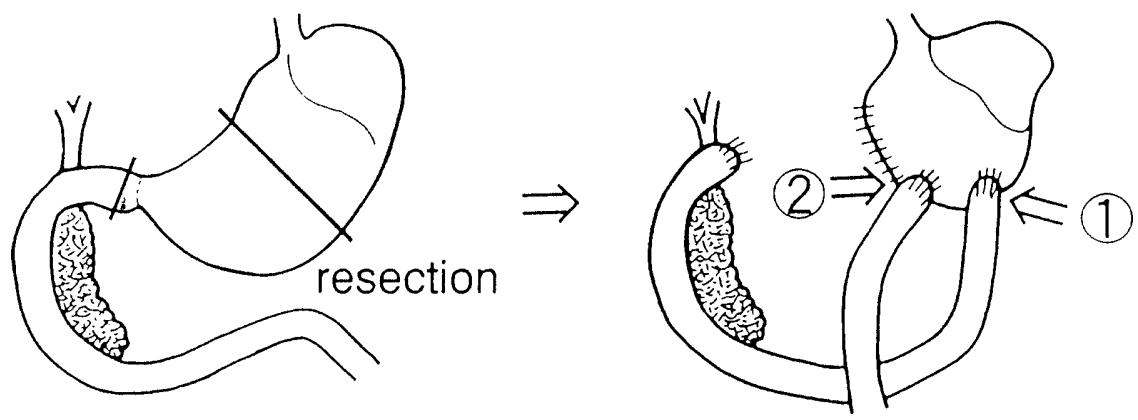

Fig. 1. Model of duodenogastric reflux. (1) Anastomosis of afferent loop; (2) anastomosis of efferent loop (from Kondo et al. [33], with permission)

\section{Animal models of duodenogastric reflux without carcinogen}

In 1979, Schlake and Nomura [31] performed gastrectomy, with the B I procedure, in male Wistar rats. At 104 weeks after the operation, a few carcinomas were found to have developed, without MNNG having been used. As far as I know, the study by these two authors is the first report of an experimental carcinoma developed without the use of MNNG. Langhans et al. [32] performed various surgical procedures in female Wistar rats. The rate of carcinomas arising in the gastric remnant correlated closely with the intensity of the duodenogastric reflux provoked by the different procedures. At 56 weeks, gastroenterostomy without any resection produced the highest tumor incidence.

We [26] reported a reflux model in rats, in which duodenogastric reflux to the remnant stomach, via the diversion of the duodenal contents through the afferent and efferent loops, produced cancerous changes in the gastric mucosa adjacent to the afferent stoma (Fig. 1). In the time-course after the operation, adenocarcinoma was first identified at 20 weeks, substantially earlier than the interval reported by others. One reason for this finding may be that the duodenogastric reflux induced by the reflux model injured the gastric mucosa more quickly and more extensively than the reflux resulting from the B I or the B II procedure. Of particular interest is that invasive growth of the cancerous tissue into the liver was observed in one animal. Such a marked growth of cancer, either with or without the administration of MNNG, has not been reported previously [33].

From another perspective on duodenogastric reflux, Miwa et al. [34] reported that duodenogastric reflux in the rat had potent carcinogenic activities, not only in the fundic mucosa through the stoma but also in the pyloric mucosa through the pylorus. Furthermore, they $[35,36]$ demonstrated that chronic reflux of the duodenal contents induced squamous cell carcinoma of the lower esophagus and forestomach. Kaminishi et al. [37,38] investigated the effect of gastric mucosal denervation on gastric carcinogenesis by using rat models in which no carcinogenic agent was given. In animals with B-I and B-II gastrectomy with vagotomy, there was a higher incidence of carcinoma at the anastomotic site than in those animals without vagotomy.

Kobayasi et al. [39] evaluated the morphological and phenotypic patterns of the adenocarcinomas induced by the B II procedure in the rat. Because all of the adenocarcinomas were intestinal type, they considered that the anomalous epithelial proliferation in the B II stoma may have led to adenocarcinoma. Whether physiological duodenal juice can induce carcinoma is an important question, and this question should be studied from various aspects [40].

\section{Which fraction of the duodenogastric contents is responsible for gastric carcinogenesis in the rat?}

Several experiments without MNNG have been done in animal models subjected to the diversion of bile juice. Mason [41], Mason et al. [42], and Mason and Filipe [43] examined male Wistar rat models to determine which fraction of the duodenogastric reflux was carcinogenic (Fig. 2). No carcinomas were found in animals with bile reflux alone, but adenocarcinoma and adenocystic proliferation were detected in animals with pancreaticoduodenal reflux, either alone or in combination with bile reflux. We [44] made a reflux model in which the bile or pancreatic juice could reach the remnant stomach through the afferent loop via a bile duct diversion. We also found carcinomas in rats with pancreaticoduodenal reflux alone and in rats with pancreaticoduodenal reflux in combination with bile reflux. These findings suggest the primary importance of pancreatic reflux. However, it is not clear whether pancreatic juice has an action that promotes gastric carcinogenesis.

On the other hand, Miwa et al. [45] reported that, in their models, the incidence of carcinoma was significantly higher in animals with bile reflux or combined reflux than in animals without reflux. This result, again, shows the importance of the bile juice, as indicated by earlier research. 


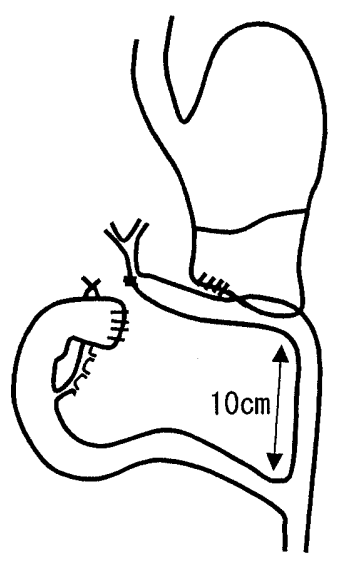

Bile reflux

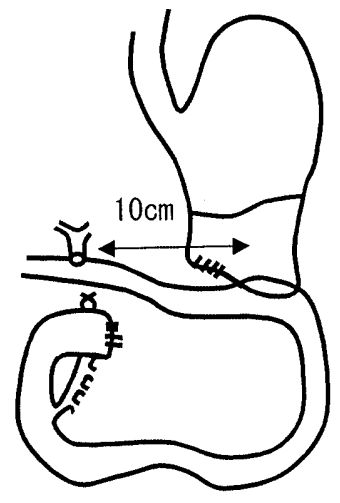

Pancreaticoduodenal reflux
Fig. 2. Operative procedure (from Mason et al. [42], with permission)

\section{Mucosal injury and cell proliferation induced by bile juice}

Many reports [46-48] have already linked bile acids, the main component of the duodenal juice, to the development of colorectal cancer. Secondary bile acids, in particular, deoxycholic acid (DCA), have been shown to act as cocarcinogens in the colon in experimental studies and to be increased in patients with colorectal cancer. Recently, Powolny et al. [49] showed that deoxycholate induced DNA damage and apoptosis in human colon epithelial cells.

The cocarcinogenic effect of bile acids has also been suggested to be involved in the experimental development of gastric cancer. Although the carcinogen contained in bile juice was not identified, nitrosated derivatives of taurocholic and glycocholic bile acids induced gastric tumors in rats [50]. Kobori et al. [51] administered MNNG and then sodium taurocholate (TCA) with food to Wistar rats, and found a significant difference in the incidence of hyperplastic and neoplastic lesions in the stomach mucosa between the TCAand the non-TCA groups, suggesting the promoting effect of TCA in tumorigenesis. Kaibara et al. [52] also suggested an enhancing effect of DCA in stomach carcinogenesis.

Furihata et al. [53] administered various bile acids to F344 rats, and measured DNA synthesis and ornithine decarboxylase (ODC) activity in the mucosa in the glandular stomach. Their experiment suggested that six bile acids, but not taurolithocholic acid sodium salt, had potential tumor-promoting activities in the pyloric mucosa of the rat stomach. Furihata et al. [54] also reported that sodium taurocholate and MNNG induced a transient increase in c-fos and c-myc expression in the py- loric gland of F344 rats [54]. These results demonstrated the carcinogenic promoting activity of bile acids, although none of these experiments proved that bile acid itself is an initiator.

Some clinical studies have investigated the relationship between bile reflux and stomach carcinogenesis in general. Bile reflux is often observed after cholecystectomy; a cohort study therefore examined cholecystectomy as a risk factor for gastric cancer [55], but their finding showed that cholecystectomy did not seem to be associated with an increased risk of gastric cancer. Fracchia et al. [56] studied biliary bile acid composition in gastric cancer patients and healthy controls, and found that gastric cancer was not associated with increased levels of the more toxic secondary bile acids, especially DCA. Of particular interest, we [57] experienced two patients with double choledochus with ectopic drainage into the stomach associated with early gastric carcinoma. A possible relationship was suspected between the direct flow of bile juice into the stomach and the development of gastric cancer. In remnant stomachs, carcinogenesis involving bile juice is thought to be related to the altered environment caused by the operation. Several reports, for example, have referred to the involvement of $\mathrm{pH}$ above 4.0 [58] or the presence of bacterial flora and unconjugated bile acids in the gastric juice $[59,60]$.

Thus, clinical as well as experimental observations have underscored the important role of bile juice in the development of gastric stump carcinoma, but the mechanism of the action of bile juice in this regard is still unknown. Evaluation of gastric mucosal polyamines, which are involved in cell proliferation, revealed a positive correlation between fasting bile reflux and concentrations of these polyamines [61]. A higher polyamine concentration was observed after the B II procedure than after cholecystectomy. Dyke et al. [62] measured DNA adduct levels in gastric mucosa after various forms of gastric surgery, and found these levels to be significantly higher in patients after truncal vagotomy than after highly selective vagotomy. Intragastric bile concentrations were also considerably higher after truncal vagotomy. The persistence of non-repaired DNA adducts could lead to mutation, and therefore, to the initiation of carcinogenesis.

\section{Duodenogastric reflux and gastritis cystica polyposa (GCP)}

In 1972, Littler and Gleibermann [63] reported that polypoid tumor developed in human gastric mucosa adjacent to B II stoma. Based on the characteristic changes in hyperplastic foveolar epithelia and the multiple cystically dilated glands seen in the lower half of 
these atypically hyperplastic lesions, they termed these tumors "gastritis cystica polyposa." Stomal polyps with the same histological features have subsequently been reported [64-67]. In Japan, Koga et al. [68] reported four patients with stomal polyps at a B II anastomosis; they called such lesions "stomal polypoid hypertrophic gastritis" to definitively differentiate the lesions from stump carcinoma. The etiology and pathogenesis of GCP have been considered to be chronic inflammation, as a consequence of the suture technique itself, or as a consequence of duodenogastric reflux into the gastric remnant.

The sites of development and the histological features of GCP resemble those of the experimental stomal polyps that precede carcinoma in rats after partial gastrectomy [67]. In our reflux model, polypoid lesions were found as areas of atypical hyperplasia near the anastomosis of the afferent loop, with duodenogastric reflux. The development of adenocarcinoma was intimately connected with the atypical hyperplasia seen in the mucosal or submucosal layer [33]. These findings suggested that direct contact of the duodenal juice with the gastric mucosa induces atypical hyperplasia and carcinoma in the anastomotic lesion. However, Kobayasi et al. [39] demonstrated the reversibility of adenomatous hyperplasia in the gastric stump in rats after the diversion of duodenogastric reflux, via B II and Rouxen-Y surgical procedures [40]. Thus, from the experimental evidence only, we cannot conclude that such adenomatous hyperplasia or GCP are precancerous changes.

Concerning the histogenesis of stump carcinoma, it is difficult to confirm a relationship with GCP. In 1975, Qizilbash [69] reported the association of GCP with stump carcinoma for the first time. Because atrophic gastritis and intestinal metaplasia were not involved in this association, he suggested that the process of carcinogenesis in stump carcinoma associated with GCP was different from that in other stump carcinomas. Bogomoletz et al. [70] showed a transition of the mucin profile between nonneoplastic and neoplastic cells in their study of six cases of stump carcinoma associated with GCP. Intestinal metaplasia did not appear to play a major role in these cases. In Japan, several reports have documented GCP associated with early gastric stump carcinoma after the B II procedure [71-73]. Characteristically, the foci of differentiated type adenocarcinoma are found in the superficial layer of GCP. The degree of intestinal metaplasia in the surrounding mucosa is low. These findings suggest a relationship between GCP and gastric type adenocarcinoma [74].

\section{Outlook for investigations of the role of duodenogastric reflux in gastric carcinogenesis in general}

Duodenogastric reflux, including bile reflux, after the B II procedure for benign disease is the factor most frequently proposed being important in relation to the occurrence of stump carcinoma. The results of many experiments with rats have already supported the idea that duodenogastric reflux may have a carcinogenic effect in the stomach. In recent years, surgical treatment for peptic ulcer has been rare, because of the development of the $\mathrm{H} 2$ blocker drugs. Although the population at risk of gastric stump carcinoma that develops after surgery for benign disease will diminish significantly in the near future, the incidence of stump carcinoma after surgery for malignant disease has been increasing [75]. The influence of duodenogastric reflux in the gastric remnant after surgery for malignant disease $[23,76]$ may differ from the influence shown after surgery for benign disease.

However, the problem of duodenogastric reflux may also have some relationship with the development of gastric carcinoma in general. Helicobacter pylori is considered to be a major risk factor for gastric cancer. It has been shown that $H$. pylori and bile reflux have a synergistic effect on gastric epithelial cell proliferation [77,78]. In the latest research, the incidence of $H$. pylori and Epstein-Barr virus infections in patients with stump carcinoma and those with gastric carcinoma in general has suggested an the etiological difference between these carcinomas [79]. Further study of these differences may contribute to our understanding of gastric carcinogenesis in general.

\section{References}

1. Freedman MA, Berne CJ. Gastric carcinoma of gastrojejunal stoma. Gastroenterology 1954;27:210-17.

2. Heinzel J, Laqua H. Magencarcinome nach fruherner Resektion wegen Ulcus ventriculi bzw.duodeni. Langenbecks Arch Chir 1954;278:87-95.

3. Christer S. Long-term prognosis after partial gastrectomy for gastroduodenal ulcer. World J Surg 2000;24:307-14.

4. Lundegradh G, Adami HO, Helmick C, Zack M, Meirik O. Stomach cancer after partial gastrectomy for benign ulcer disease. N Engl J Med 1988;319:195-200.

5. Caygill CP, Hill MJ, Kirkham JS, Northfield TC. Mortality from gastric cancer following gastric surgery for peptic ulcer. Lancet 1986;: :929-31.

6. Viste A, Bjonesttad E, Opheim P, Thunold J, Hartveit F, Eide $\mathrm{GE}$, et al. Risk of carcinoma following gastric operations for benign disease. A historical cohort study of 3470 patients. Lancet 1986;II:502-5.

7. Domellof L, Janunger KG. The risk for gastric carcinoma after partial gastrectomy. Am J Surg 1977;134:581-4.

8. Fischer AB, Graem N, Jensen OM. Risk of gastric cancer after Billroth 2 resection for duodenal ulcer. Br J Surg 1983;70:552-4. 
9. Toftgaard C. Gastric cancer after peptic ulcer surgery. Ann Surg 1989;210:159-64.

10. Tokudome S, Kono S, Ikeda M, Kuratsune M, Sano C, Inokuchi $\mathrm{K}$, et al. A prospective study on primary gastric stump cancer following partial gastrectomy for benign gastroduodenal diseases. Cancer Res 1984;44:2208-12.

11. Asano A, Mizuno S, Sasaki R, Aoki K, Yokoyama H, Yokoyama $\mathrm{Y}$. The long term prognosis of patients gastrectomized for benign gastroduodenal diseases. Jpn J Cancer Res 1987;78:337-48.

12. Kondo K, Yamauchi M, Sasaki R, Akiyama S, Watanabe T, Yokoyama Y, Takagi H. Statistical and pathological study of carcinoma in the gastric remnant (in Japanese with English abstract). Nippon Shoukaigeka Gakkai Zasshi (Jpn J Gastroenterol Surg) 1991;24:2105-12.

13. Peitsch W, Becker HD. Frequency and prognosis of gastric stump cancer. Front Gastrointest Res 1979;5:170-7.

14. Dahm K, Eichfuss HP, Koch W. Cancer of the gastric stump after Billroth II resection. Front Gastrointest Res 1979;5:1649.

15. Hammar E. The localization of precancerous changes and carcinoma after previous gastric operation for benign condition. Acta Pathol Microbiol Scand Sect 1976;84:495-507.

16. Kosaka T, Kamata T, Fujimura T, Hasegawa H, Yonemura Y, Miwa K, Miyazaki I. A study of 29 patients with cancers of the gastric remnant - a speculation on a remnant cancer-promoting factor from the aspect of tumor location (in Japanese with English abstract). Nippon Geka Gakkai Zasshi (J Jpn Surg Soc) 1990;91:340-7.

17. Giacosa A, Molinari F, Perasso A, Cheli R. Endoscopic experience in the diagnosis of gastric stump cancer. Front Gastrointest Res 1979;5:160-3.

18. Correa P, Haenszel W, Cuello C, Zavala D, Fontham E, Zarama $\mathrm{G}$, et al. Gastric precancerous process in a high risk population : cohort follow-up. Cancer Res 1990;50:4737-40.

19. Janunger KG, Domellof L, Eriksson S. The development of mucosal changes after gastric surgery for ulcer disease. Scand $\mathbf{J}$ Gastroenterol 1978;3:217-23.

20. Bedossa P, Lemaigre G, Martin ED. Histochemical study of mucosubstances in carcinoma of gastric remnant. Cancer 1987;60: 2224-7.

21. Lo SS, Tsay SH, Wu CW, Hsieh MC, Li AF, Lui WY. Intestinaltype tumor in resected gastric remnant cancer. J Gastroenterol Hepatol 1997;12:434-6.

22. Furukawa H, Iwanaga T, Hiratsuka M, Imaoka S, Ishikawa $\mathrm{O}$, Kabuto $\mathrm{T}$, et al. Gastric remnant cancer as a metachronous multiple lesion. Br J Surg 1993;80:54-6.

23. Kaminishi M, Shimizu N, Yamaguchi H, Hashimoto M, Sakai S, Oohara T. Different carcinogenesis in the gastric remnant after gastrectomy for gastric cancer. Cancer 1996;77:1646-53.

24. Peraino C, Fly RJ, Staffeldt E. Reduction and enhancement by phenobarbital of hepatocarcinogenesis induced in the rat by 2-acetylaminofluorence. Cancer Res 1971;31:1506-12.

25. Sugimura T, Fujimura S. Tumor production in the glandularstomach and alimentary tract of the rat by $\mathrm{N}$-methyl- $\mathrm{N}^{\prime}$-nitro-Nnitrosoguanidine. Nature 1967;216:943-4.

26. Kondo K, Suzuki H, Nagayo T. The influence of gastro-jejunal anastomosis on gastric carcinogenesis in rats. Jpn J Cancer Res 1984;75:362-9.

27. Salmon RJ, Merle S, Zafrani B, Decosse JJ, Sherloch P, Deschner EE. Gastric carcinogenesis induced by N-methyl-N'nitrosoguanidine: role of gastrectomy and duodenal refulux. Jpn J Cancer Res 1985;76:167-72.

28. Nishidoi H, Koga S, Kaibara N. Possible role of duodenogastric reflux on the development of remnant gastric carcinoma induced by $\mathrm{N}$-methyl- $\mathrm{N}^{\prime}$-nitro-N-nitrosoguanidine in rats. $\mathrm{J}$ Natl Cancer Inst 1984;72:1431-5.

29. Dahm K, Eichen R, Mitschke H. Cancer risk of the stomach resected for ulcer. The role of duodenogastric reflux (author's translation). Langenbecks Arch Chir 1977;4,344:71-82.
30. Schlag P, Meister H, Feyerabend G, Merkle P. Influence of duodenal reflux on the epithelium of gastroduodenal anastomosis (author's translation). Langenbecks Arch Chir 1977;344:207-17.

31. Schlake W, Nomura K. Histogenesis of carcinoma in the glandular stomach of the rat after BI resection. Curr Top Pathol 1979;67:1-67.

32. Langhans P, Hegar RA, Hohenstein J, Schlake W, Bunte H. Operation-sequel carcinoma of the stomach. Experimental studies of surgical techniques with or without resection. World J Surg 1981;5:595-605.

33. Kondo K, Kojima H, Akiyama S, Ito K, Takagi H. Pathogenesis of adenocarcinoma induced by gastrojejunosotomy in Wistar rats: role of duodenogastric reflux. Carcinogenesis 1995;16:1747-51.

34. Miwa K, Hasegawa H, Fujimura T, Matsumoto H, Miyata R, Kosaka T, et al. Duodenal reflux through the pylorus induces gastric adenocarcinoma in the rat. Carcinogenesis 1992;13:231316.

35. Miwa K, Hattori T, Miyazaki I. Duodenogastric reflux and foregut carcinogenesis. Cancer 1995;76(Suppl 6):1426-32.

36. Miwa K, Segawa M, Takano Y, Matsumoto H, Sahara H, Yagi M, et al. Induction of oesophageal and forestomach carcinomas in rats by reflux of duodenal contents. Br J Cancer 1994;70:185-9.

37. Kaminishi M, Shimoyama S, Yamaguchi H, Ogawa T, Kawahara M, Jojima Y, Ohara T. Effect of gastric mucosal denervation on gastric carcinogenesis (in Japanese with English abstract). Nippon Geka Gakkai Zasshi (J Jpn Surg Soc) 1992;93:927-31.

38. Kaminishi M, Shimizu N, Shimoyama S, Yamaguchi H, Ogawa T, Sakai S, et al. Etiology of gastric remnant cancer with special reference to the effects of denervation of the gastric mucosa. Cancer 1995;75:1490-6.

39. Kobayasi S, Tatematsu M, Ogawa K, de Camargo JL, Rodrigues MA, Ito N. Reversibility of adenomatous hyperplasia in the gastric stump after diversion of bile reflux in rats. Carcinogenesis 1991;12:1437-43.

40. Meister H, Schlag P, Weber E, Bockler R, Merkle P. Frequency of cancerous and precancerous epithelial lesions in the stomach in different models for enterogastric reflux. Scand J Gastroenterol Suppl 1981;67:165-8.

41. Mason RC. Duodenogastric reflux in rat gastric carcinoma. Br J Surg 1986;73:801-3.

42. Mason RC, Taylor PR, Filipe MI, McColl I. Pancreaticoduodenal secretions and the genesis of gastric stump carcinoma in the rat Gut 1988;29:830-4.

43. Mason RC, Filipe, I. The aetiology of gastric stump carcinoma in the rat. Scand J Gastroenterol 1990;25:961-5.

44. Kojima H, Kondo K, Takagi $\mathrm{H}$. The influence of reflux of bile and pancreatic juice on gastric carcinogenesis in rats (in Japanese with English abstract). Nippon Geka Gakkai Zasshi (J Jpn Surg Soc) 1990;91:818-26.

45. Miwa K, Fujimura T, Hasegawa H, Kosaka T, Miyata R, Miyazaki I, Hattori T. Is bile or are pancreaticoduodenal secretions related to gastric carcinogenesis in rats with reflux through the pylorus? J Cancer Res Clin Oncol 1992;118:570-4.

46. Chomchai C, Bhadrochari N, Nigro ND. The effect of bile on the induction of experimental intestinal tumors in rats. Dis Colon Rectum 1973;17:310-12.

47. Hill MJ. The role of colon anaerobes in the metabolism of bile acids and steroids, and its relation to colon cancer. Cancer 1975;36:2387-400.

48. Reddy BS, Watanabe K, Weisburger JH, Wynder EL. Promoting effect of bile acids in colon carcinogenesis in germ-free and conventional F344 rats. Cancer Res 1977;37:3238-42.

49. Powolny A, Xu J, Loo G. Deoxycholate induces DNA damage and apoptosis in human colon epithelial cell expressing either mutant or wild-type p53. Int J Biochem Cell Biol 2001;33:193-203.

50. Busby WF, Shuker DE, Charnley G, Newberne PM, Tannenbaum SR, Wogan GN. Carcinogenicity in rats of the nitrosated bile acid conjugates $\mathrm{N}$-nitrosoglycocholic acid and N-nitrosotaurocholic acid. Cancer Res 1985;45:1367-71. 
51. Kobori O, Shimizu T, Maeda M, Atomi Y, Watanabe J, Shoji M, Morioka Y. Enhancing effect of bile and bile acid on stomach tumorigenesis induced by $\mathrm{N}$-methyl- $\mathrm{N}^{\prime}$-nitro- $\mathrm{N}$ nitrosoguanidine in Wistar rats. J Natl Cancer Inst 1984;73:85361.

52. Kaibara K, Takebayasi M, Koga H. Deoxycholic acids as a promoter in the development of gastric carcinoma induced by $\mathrm{N}$ methyl-N'-nitro-N-nitrosoguanidine in rats. The Cancer Journal 1988;2:14-16.

53. Furihata C, Takezawa R, Matushima T. Potential tumorpromoting activity of bile acids in rat glandular stomach. Jpn J Cancer Res 1987;78:32-9.

54. Furihata C, Yamakoshi A, Hatta A, Tatematsu M, Iwata H, Hayashi K, et al. Induction of c-fos and c-myc oncogene expression in the pyloric mucosa of rat stomach by N-methyl-N'-nitroN-nitrosoguanidine and taurocholate. Cancer Lett 1994;83: 215-20.

55. Gustavsson S, Adami HO, Meirik O, Nyren O, Krusemo UB. Cholecystectomy as a risk factor for gastric cancer. A cohort study. Dig Dis Sci 1984;29:116-20.

56. Fracchia M, Pellegrino S, Secreto P, Calgaro M, Taraglio S, Pera A, Galatiola G. Biliary bile acid composition in gastric cancer. Int J Clin Lab Res 1999;29:46-8.

57. Kondo K, Yokoyama I, Yokoyama Y, Harada A, Nagayo T. Two cases of gastric cancer-bearing double choledochus with ectopic drainage into the stomach. Cancer 1986;57:13841.

58. Watt PCH, Sloan JM, Donaldson JD. Relationship between histology and gastric juice $\mathrm{pH}$ and nitrite in the stomach after operation for duodenal ulcer. Gut 1980;25:246-52.

59. Domellof L, Reddy BS, Weisburger JH. Microflora and deconjugation of bile acid in alkaline reflux after partial gastrectomy. Am J Surg 1980;140:291-5.

60. Muscroft TJ. The microflora of the postoperative stomach. Br J Surg 1981;68:560-4.

61. Lorusso D, Linsalata M, Pezzolla F, Berloco P, Osella AR, Guerra V, et al. Duodenogastric reflux and gastric mucosal polyamines in the nonoperated stomach and in the gastric remnant after Billroth II gastric resection. A role in gastric carcinogenesis? Anticancer Res 2000;20:2197-201.

62. Dyke GW, Craven JL, Hall R, Garner RC. DNA damage in the stomach after vagotomy measured by $32 \mathrm{P}$-postlabelling. Gut 1993;34:1683-7.

63. Littler ER, Gleibermann E. Gastritis cystica polyposa. Cancer 1972;29:205-9.

64. Jablokow VR, Aranha GV, Reyes CV. Gastric stomal polypoid hyperplasia: report of four cases. J Surg Oncol 1982;19:106-8.
65. Stemmermann GN, Hayashi T. Hyperplastic polyps of the gastric mucosa adjacent to gastroenterostomy stomas. Am J Clin Pathol 1979;71:341-5.

66. Grieffel B, Engleberg M, Reiss R. Multiple polypoid cystic gastritis in old gastroenteric stoma. Arch Pathol 1974;97:316-18.

67. Franzin G, Musola R, Zamboni G, Manfrini C. Gastritis cystica polyposa: a possible precancerous lesion. Tumori 1985;71:13-18.

68. Koga S, Watanabe H, Enjoji M. Stomal polypoid hypertrophic gastritis lesion at gastroenterostomy site. Cancer 1979;43:647-57.

69. Qizilbash AH. Gastritis cystica and carcinoma arising in old gastrojejunostomy stoma. CMA J 1975;112:1432-3.

70. Bogomoletz WV, Potet F, Barge J, Molas G, Qizilbash AH. Pathological features and mucin histochemistry of primary gastric stump carcinoma associated with gastritis cystica polyposa. A study of six cases. Am J Surg Pathol 1985;9:401-10.

71. Aoyagi K, Koufuji K, Yano S, Murakami N, Terasaki Y, Yamasaki Y, et al. Two cases of cancer in the remnant stomach derived from gastritis cystica polyposa. Kurume Med J 2000;47: 243-8.

72. Tanahashi Y, Ohwada S, Takubo K, Miyamoto Y, Takeshita M, Uchida $\mathrm{O}$, et al. A case of early carcinoma of the remnant stomach (in Japanese with English abstract). Gan No Rinsho (Jpn J Cancer Clin) 1990;36:929-33.

73. Matsuda I, Konno H, Maruo Y, Tanaka T, Baba M, Nishino N, Nakamura $\mathrm{S}$, et al. A case of triple early gastric cancer in the remnant stomach. Am J Gastroenterol 1995;90:1016-18.

74. Hattori T. Morphological range of hyperplastic polyps and carcinoma arising in hyperplastic polyp of the stomach. J Clin Pathol 1985;38:622-30.

75. Kaneko K, Kondo H, Saito D, Shirao K, Yamaguchi H, Yokota T, et al. Early gastric stump cancer following distal gastrectomy. Gut 1998;43:342-4.

76. Matsui N, Yao T, Akazawa K, Nawata H, Tsuneyoshi M. Different characteristics of carcinoma in the gastric remnant: histochemical and immunohistochemical studies. Oncol Rep 2001;8:17-26.

77. Lynch DA, Mapstone NP, Clarke AM, Jackson P, Quirke P, Axon AT. Cell proliferation in the gastric corpus in Helicobacter pylori-associated gastritis and after gastric resection. Gut 1995; 36:351-3.

78. Zullo A, Rinaldi V, Hassan C, Lauria V, Attili AF. Gastric pathology in cholecystectomy patients: role of Helicobacter pylori and bile reflux. J Clin Gastroenterol 1998;27:335-8.

79. Baas IO, Rees BP, Musler A, Craanen ME, Tytgat GN, Berg FM, Offerhaus GJ. Helicobacter pylori and Epstein-Barr virus infection and p53 tumor suppressor pathway in gastric stump cancer compared with carcinoma in the non-operated stomach. J Clin Pathol 1998;51:662-6. 